\title{
La poesía de César Moro y el pensamiento mítico. Una aproximación
}

\author{
Camilo Fernández Cozman \\ Departamento Académico de Literatura
}

César Moro (1903-1956) es un poeta incomprendido. La crítica aún no puede asediar el sentido de este torrente de imágenes oníricas. Los estudiosos se han detenido frecuentemente en los detalles de su vida y han olvidado al artista -dibujante y escritor-que revelaba una pertinaz fidelidad a la palabra poética. Pilar de la tradición literaria peruana, Moro fue un militante del movimiento surrealista. Pero el surrealismo no era para él un conjunto de recetas aprendidas de memoria, sino una experiencia vital, un proyecto que comprometía la totalidad de su existencia.

Moro escribió pognås encéstellano y frānoés. Buena parte de su obra fue producida en la lengua de Baudelaire y de Rimbaud. Resulta a todas luces sorprendente que llegara a manejar el frances hasta distinguir sus más leves sonidos, sus matices sintácticos, sus resonancias semánticas. Y por último es asombroso que pudiera hacer suyo un idioma ajeno, extraño. No cabe duda de que escribir excelente poesía en una segunda lengua es una labor de titanes y Moro fue uno de ellos.

El propósito de este ensayo es abordar la poesía de Moro como la expresión de un pensamiento mítico. Cabe advertir que nuestro análisis se centrará sobre todo en la hermenéutica temático-simbólica de las Cartas (1939), aunque tal vez ciertas conclusiones de este artículo puedan servir para la interpretación de otros poemarios de Moro. Vamos a poner de relieve el análisis textual y, cuando creamos conveniente, recurriremos a un marco teórico específico que será empleado de manera operativa. Intentamos plantear la necesidad de una 
lectura antropológica de la poesía moreana. Es decir, superar el sociologismo y asediar el universo simbólico de esta escritura que no debe ser estudiada desde un punto de vista biografista, en vista de que, como bien remarca Ezra Pound, «[s]e puede reconocer a un mal crítico cuando empieza a discutir al poeta y no al poema» ${ }^{1}$.

En las páginas que siguen intentamos una primera lectura de las Cartas sobre la base de un modelo interdisciplinario que permita abrir un abanico de posibilidades significativas porque las particularidades de lírica de Moro nos llevan al tiempo del origen, al poste cósmico de ordenación del mundo y a la piedra sagrada. El pensamiento metafórico que brota en esta poesía tiene connotaciones míticas. Es increíble que los críticos las hayan olvidado para centrarse de modo tendencioso en la vida del autor y reducir el texto a una mera página biográfica.

\section{EL PENSAMIENTO MITICO EN LAS CARTAS DE CESAR MORO}

La crítica tradicional hadifundido una vacua ficción en nuestras mentes, pues afirma que por un lado están los indigenistas y, por el otro, los cosmopolitas. Se habla, en consecuencia, de compartimentos estancos. Ésta es una visión trasnochada que tièe nimetosas. limitaciontes para comprender la especificidad de la cultura latimoamèricanånEl cảadedéésar Moro sirve para derruir los prejuicios que pululan en el ámbito de la crítica tradicional. Como lo ha señalado Emilio Adolfo Westphalen,

Moro no renegó nunca de su pasado ni de su tradición, aunque él podría decir que su pasado, que $s u$ tradición no tenían por qué ser los nuestros. En unas líneas postrimeras y que aparecieran póstumamente en L'art magique de André Breton y Gerard Legrand (Paris, 1956), le vemos reconocerse esas raíces profundas (por tanto invisibles) en un paisaje concreto y en una antigua cultura aún viva para él. «No en vano -leemos allí- he nacido cuando miles y miles de peruanos están todavía por nacer, en el país consagrado al sol y tan cerca del valle de Pachacámac, en la costa fértil en culturas mágicas, bajo el vuelo majestuoso del divino pelícano tutelar». 
No en vano, añadiremos nosotros, supo teñir con esa magia su pintura y su poesía?.

Moro tuvo una concepción religiosa de la naturaleza. En «Breve comentario bajo el cielo de México" ${ }^{3}$, evoca la figura de Ehécatl, dios del viento, que posee una «máscara de ave de pico 'bravo y rojo'». Ehécatl es un «Dios de estatura humana, sólido y terrestre ${ }^{4}$. Moro se identifica con él y llega a decir que:

Yo respiro aire milenario de culturas refinadas y difuntas - tan afines a mi interno código- bocanadas de humo purísimo, inmarcesible al grito amorfo de la realidad, bajo el cielo entrañable ${ }^{5}$.

Se observa que el poeta asume una parte del pasado como propia. Reconoce al mundo prehispánico como un importantísimo componente de su interioridad. Respira un aire milenario y, por lo tanto, su subjetividad se halla insuflada por las culturas prehispánicas. México aparecerá en las Cartas simbolizado en la figura de Antonio, pues se afirma que la ciudad de México crece alrededor de este último.

En «Escultura azteca» ${ }^{6}$, Moro nos habla de

los testimonios pétreos de las civilizaciones aladas, dinámicas, ya

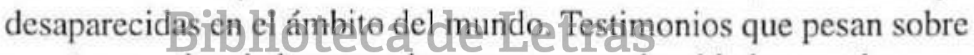
nuestra conciencia hymana. hoy con mayor densidad angustiosa, en esta hora crudefísıma de prueba en la que no sabríamos determinar si definitivamente muere un presente que ya nos estamos acostumbrando a mirar como el espejismo aun resplandeciente del objeto lejano. Testimonios de piedra «Hablando un lenguaje de piedra $-\mathrm{Al}$ oído del viento». Lenguaje más y más angustioso, desaparecidas las causas que lo suscitaron, los ojos que ávidamente lo contemplaron en una persuasión de eternidad en el espacio y en el tiempo ${ }^{7}$.

Westphalen. Emilio Adolfo. Escritos sobre ante y poesia. México. Fondo de Cultura Económica, 1986, p. III.

Moro. César. Los anteojos de azufre. Lima, Ed. San Marcos, 1958, pp. 79-84.

Ibidem. p. 80.

Ibidem.

Ibidem. pp. 33-34.

Ilsidem. p. 33 
El lenguaje es de piedra. Ésta permite la comunicación. En la civilización azteca, la piedra tuvo un contenido sagrado. Y el testimonio (aquello que la civilización dejó bajo sus escombros) se halla grabado en la piedra. También en las Cartas la piedra se asocia al universo de lo sagrado. Por eso, no es posible leer esos versos sin la presencia de los dos textos antes mencionados, en los cuales Moro reflexiona acerca del pasado prehispánico. Entonces, se tejen complejas relaciones intertextuales y, por eso, es ingenuo no relacionar la poesía de Moro con sus textos en prosa.

¿Quién es el personaje central de las Cartas de Moro? Es sin duda ANTONIO. Su nombre está escrito con mayúsculas. Es un vocablo mágico. Se trata de un Dios, según el yo poético. Tiene el nombre de una divinidad del mundo prehispánico: el Sol, que se asocia en el texto de Moro a los incas. El poeta dice que "ANTONIO es Dios/ ANTONIO es el Sol/ [...] el Emperador el Inca» ${ }^{8}$. Tiene la capacidad de destruir y de crear. Favorece el tránsito desde el día a la noche y viceversa. El poeta, así, hace referencia al paso del orden al caos, que es fundamental en las cosmovisiones míticas. En innúmeros mitos, se cuenta que por la acción de un dios el caos se troca en orden.

"ANTONIO" constituye el origen de la Vía Láctea y puede erigir nuevos continentes. Se trata de una palabra que remite al momento de los orígenes. En un tiempo mítico surgió la Vía Láctea. Como nos recuerda Mircea Eliade, la creación tuvo lugar empinjinstantein dilg tempore ${ }^{y}$. El acto creador se reitera y, de ese modo, constituye «una repetición simbólica del nacimiento de los mundos» ${ }^{10}$. Por eso, la palabra «ANTONIO» se itera a lo largo del poema, pues quiere decir "creación» y ésta se evoca a través de repeticiones discursivas que evocan ricas connotaciones simbólicas.

El poeta señala que "ANTONIO tiene pies de constelaciones". ¿Qué es una constelación? Es un «conjunto de estrellas que, mediante trazos imaginarios sobre la aparente superficie celeste, forman un dibujo que evoca determinada figura (un animal, un personaje mitológico, etc.)»" Sin duda, ANTONIO tiene pies «aéreos» y la forma de éstos nos recuerda el funcionamiento de figu-

* Moro. César. Ohra poética. Lima, INC. 1980, p. 73.

- Quiere decir en wen aquel tiempo". Se trata de un tiempo no histórico, de un tiempo mítico.

10 Eliade. Mircea. Tratado de historia de las religiones. Madrid, Instituto de Estudios Políticos. 1954 , p. 206.

4 Real Academia Española. Diccionario de la lengua española. Madrid, Ed. Espasa-Calpe, 1995. t. 1. p. 549. 
ras mitológicas que, desde el punto de vista cósmico, llenan el universo con su inmensidad.

Se afirma de manera categórica: «México crece alrededor de ANTONIO». En efecto, Antonio decide la presencia del orden o del caos. En el poema se percibe, como en un discurso mítico, un tránsito de la destrucción al origen, del caos al orden:

ANTONIO es Dios

ANTONIO es el Sol

ANTONIO puede destruir el mundo en un instante

ANTONIO hace caer la lluvia

ANTONIO puede hacer oscuro el día o luminosa la noche

ANTONIO es el origen de la Vía Láctea

Antonio permite el desarrollo de las sociedades agrícolas, pues hace crecer la lluvia. Sobre la base de este tótem el poeta realiza una clasificación de los diversos fenómenos de la naturaleza. «ANTONIO es el nombre genérico de los cuerpos celestes», vale decir, constituye una palabra sagrada, mítica. El creyente en el tótem siente placer al escribir la palabra con mayúscula porque le permite nombrar un todo cósmico. El «primitivo» manifiesta el funcionamiento de un orden, de una taxonomía analítica. Todo México crece alrededor de Antonio y, por lo tanto, los creyentes rodean al objeto de culto y le rinden pleitesía.

Antonio está situado en untremponticeo en vista de que «ocupa toda la

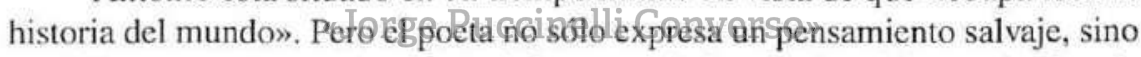
también se apropia creativamente de los conocimientos obtenidos por la ciencia occidental. Habla de «la época megalítica del Mundo», «la Dinastía de los Ptolomeos" y de «los colosos de Memmón en Tebas». Además subraya la idea de que el saber científico está provisto de enigmas que, sin embargo, el mito puede ayudar a descifrar: "ANTONIO es el corazón del mineral desconocido".

\section{I.1. El simbolismo del centro en las Cartas de Moro}

La antropología contemporánea ha puesto de relieve el simbolismo del centro como fundamento de las culturas tradicionales ${ }^{12}$. Moro dice: «Antonio es una montaña transparente». Una lectura superficial señalaría únicamente el

12 Cf Lo sugrailo y lo profano, de Mircea Eliade. 9a. edición. Bogotá. Ed. Labor, 1996, p. 37. 
funcionamiento de una metáfora a es b. Pero el mencionado verso tiene aristas semánticas mucho más complejas. He allí un viejo tópico de las culturas tradicionales porque «la Montaña Sagrada -donde se reúnen el cielo y la tierra- se halla en el centro del mundo ${ }^{13}$. En realidad, Antonio es un Axis mundi que

une, a la vez que lo sostiene, el Cielo con la Tierra, y cuya base está hundida en el mundo de abajo [...] Columna cósmica de semejante índole tan sólo puede situarse en el centro mismo del Universo, ya que la totalidad del mundo habitable se extiende alrededor suyo ${ }^{14}$.

En el verso "Antonio hace crecer la lluvia» se percibe que el Dios une el universo de lo alto -donde nace la lluvia-con el mundo de lo bajo -donde crecen los árboles y la siembra-. En la metáfora «crecer la lluvia» se manifiesta la síntesis porque la lluvia, que viene de lo alto, crece como una planta, la cual se asocia al mundo de lo bajo.

El Axis mundi implica la ruptura de la homogeneidad del espacio. Hay un centro y todo el mundo se extiende alrededor de él. Por consiguiente, el eje cósmico «se encuentra en el 'medio', en el 'ombligo de la Tierra', es el centro del Mundon ${ }^{15}$.

Antonio permite el tránsito del cielo-a la tierra. El hablante lírico elogia a la figura de Antonio y, de ese modo, se comunica con la esfera de lo alto.

\section{«Jorge Puccinelli Converso»}

1.2. El poste cósmico

El hablante lírico afirma:

Gran vendaval, dispérsame en la lluvia y en la ausencia celeste, dispérsame en el huracán de celajes que arremolina tu paso de centellas por la avenida de los dioses donde termina la Vía Láctea que nace de tu pene.

En las culturas tradicionales aparece con frecuencia un poste sagrado. "Este poste representa un eje cósmico, pues es en torno suyo donde el territorio

\footnotetext{
Eliade. Mircea. El mito del eterno retorno. México, Ed, Planeta, 1985, p. 19

Eliade, Mircea. Op. cit. p. 38.

14. thickem
} 
se hace habitable, se transforma en 'mundo'. De ahí el considerable papel ritual del poste sagrado» ${ }^{16}$.

Un famoso mito acerca del origen de los incas dice que una pareja enviada por el dios Sol llevaba una barrilla de oro y que esta última se hundió en el cerro Huanacauri. De ese modo, se relata el origen del Incanato. La barrilla de oro funciona, en este caso, como un poste cósmico de ordenación del mundo.

En las Cartas de Moro, la estructura fálica de Antonio tiene una indudable dimensión simbólica. La poesía no implica el funcionamiento de un sentido literal. Tampoco representa la biografía del escritor porque el texto construya otro referente. Como bien señala Pozuelo, la poesía es frase imaginaria. Ella «invita [...] a la imaginación; es, por tanto, acto de creación de mundos imaginarios no sujetos, por tanto, a las reglas de credibilidad» ${ }^{17}$. Aunque la lectura ingenua tradicional ha querido identificar yo=autor hombre,

el principal rasgo pragmático destacado hoy por todos los autores es el que Culler llama «distancid e impersonalidad». Según la convención de «distancia e impersonalidad»ę el valor de los deícticos y sus efectos origina un proceso de generalización según la cual el yo-tú del poema no remiten a un contexto externo real, sino a una situación ficticia que otorgue coherencia a la lectura, independientemente del referento externoteca de Letras

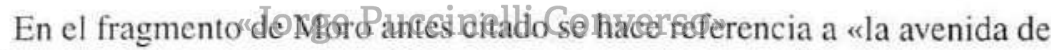
los dioses donde termina la Vía Láctea que nace de tu pene». En otro momento se dice que «ANTONIO fecunda a las estrellas» y que él es un «Hermoso demonio de la noche, tigre implacable de testículos de estrella, gran tigre de semen inagotable de nubes inundando el mundo».

No cabe duda de que la estructura fálica es un poste cósmico de ordenación del mundo. En primer lugar, de él nació la Vía Láctea. Antonio penetró a las estrellas y, por lo tanto, materializó un ritual de fecundación. El semen de Antonio es como la lluvia que inunda el mundo y facilita el desarrollo de la agricultura. El hablante lírico pone de relieve lo siguiente:

Ibidem.

Pozuelo Ivancos. José María. Teoria del lenguaje literario Madrid. Ed. Cátedra. 1989. p. 218

Iliclem, pp. 221-222. 
Cuando sonríes parece que todas las montañas del mundo tuvieran sol y árboles y que vinieran a tu encuentro a besar las huellas de tus pasos; parece que la noche se hubiera acabado para siempre y que ya sólo la luz y el amor y una inocencia cósmica reinaran sobre el universo, donde los planetas y los astros no pueden compararse a ti sino como reflejos o emanaciones de tu presencia en el mundo. Ya que en tu poder está volver sombrío el día y hacer clara la noche y desencadenar lluvias tempestuosas y hacer gemir a los elementos, ¿por qué no quieres transformarme en un pedazo de tu sombra, o en tu aliento o simplemente en una partícula de tu pensamiento?

En la expresión «hacer gemir los elementos» revela que el acto sexual es un acto creador para el poeta. Penetrar significa crear, ordenar el mundo. El poste cósmico se hace presente en las montañas. Confiere a estas últimas un contenido ritual. Por virtud del poște cósmico, las montañas se convierten en casas de culto. Él es una columna que sostiene todas las cosas. Los árboles y el sol no pueden vivir sin él.

\section{I.3. El poeta y la piedra sagrada}

La piedra es un componente fundamental de las Cartas de Moro. En los sueños del hablante linico, AntonioGapafece transformado en una piedra:

$$
\text { "Jorge Puccinelli Converso" }
$$

Manifiéstate a mí bajo tu apariencia humana; no tomes el aspecto del sol o de la lluvia para venir a verme; a veces me es difícil reconocerte en el rumor del viento o cuando en mis sueños adquieres el aspecto demasiado violento de una enorme piedra de basalto que rueda por el espacio infinito sin detenerse y me arrastra a la desolación de playas muertas que la planta del hombre no había hollado aún, playas todas negras en que una montaña que ocupa todo el horizonte sostiene una reproducción del tamaño del cielo de tu cabeza tal como yo la conozco, tu cabeza rodeada de centellas y que despide un fuego tan terrible que a veces se propaga hasta las nubes e incendia el mundo.

Antonio como un dios tiene la virtud de transformarse. Adquiere una forma de piedra o una apariencia humana. Puede tomar el aspecto del sol o de la lluvia. 
La montaña se ha constituido en una casa de cultı y, por lo tanto, sostiene una reproducción de la inmensa cabeza de Antonio. En efecto, esta última se asocia al universo de lo alto, representado por el cielo.

En los sueños suele aparecer de manera disfrazada un deseo. El lenguaje onírico y el mítico tiene obvios puntos comunes. El hablante desea que Antonio sea una piedra violenta y se vincule con el mundo de lo bajo. En las culturas tradicionales, el comportamiento del ser humano quiere imitar al de los dioses:

Haz que vuelva al origen de mi vida, a la nada, y no vuelvas a crearme ni a traerme nuevamente a la vida ni siquiera bajo la forma de una piedra; aún así tendría la nostalgia insaciable de ti, la memoria de tu recuerdo. Dispérsame en el aire o en el fuego o en el agua o mejor en la nada, fuera del mundo.

Antonio crea a los individuos, quienes adquieren la forma de una piedra. El hablante desea volver al origen, anhela la repetición de la cosmogonía. En efecto, «toda creación repite el acto cosmogonico por excelencia: la creación del mundo» ${ }^{19}$. Antonio vuelve a crear los objetos y los seres. El hablante no quiere ser una piedra, sino que prefiere fusionarse con el aire, el fuego o el agua.

\section{Biblioteca de Letras}

\section{A MANERA DE CONCLUSION}

Rasgos del pensamiento mítico están presentes en la escritura de Moro. Se han leído las Cartas desde un punto de vista biografista. Pero el texto literario es ficcional e implica una construcción y un montaje. Reducir el discurso poético a una página biográfica significa desconocer su complejidad. El poema dialoga con la cultura y no tanto con la vida del artista. Es un objeto vivo que se ha independizado de su creador para hablar de manera divina a los lectores acerca de una experiencia que adquiere una dimensión universal.

Moro escribió sobre Pachacámac. Se identificó con un pasado, sin embargo, no dejó de asumir la vanguardia como fenómeno internacional. Del mismo modo, Huidobro - poeta con el cual Moro polemizó duramente- afirmaba que

\footnotetext{
19 Eliade. Mircea. Op, cit., p. 24.
} 
la «idea del artista como creador absoluto, del Artista-Dios, me la sugirió un viejo poeta indígena de Sudamérica (aimará), que dijo: 'El poeta no es un dios; no cantes la lluvia, poeta, haz llover' $»^{20}$.

Tanto Moro cuanto Huidobro son dos casos representativos de cómo un tipo de escritura vanguardista en Hispanoamérica estuvo preocupada por los valores de las culturas marginadas.

La poesía de Moro merece una nueva lectura. No una interpretación decimonónica ni positivista. Si el mito permanece en el corazón de la vida contemporánea, entonces esta poesía mantiene vigencia e inocultable belleza.

CISNEROS, Luis Jaime.

\section{BIBLIOGRAFIA}

«Creación y surrealismo en el lenguaje». En Avatares del surrealismo en el Perú y en América Latina. Actas del coloquio internacional organizado por la Pontificia Universidad Cat師ica del Perú, la Embajada de Francia y la Alianza Francesa, en Lima, 3-4-5 de jutio 1990. Lima, Institut Français d'ÉtudesAndihesin pontifieia Universidad Católica del Perú, 1992, pp. [3]-18.

COYNE, André

César Moro. Lima, Imp. Torres Aguirre, 1956.

«César Moro: surrealismo y poesía». En Avatares..., pp. [189]-202.

\section{CHÉNIEUX-GENDRON, Jacqueline}

«Mentalités surréalistes: peut-on les décrire?». En Avatares..., pp. 21-40.

\footnotetext{
21 Huidobro, Vicente. Poesía y poética. Madrid, Alianza Editorial, 1996, pp. 88-89.
} 
ELIADE, Mircea

Tratado de historia de las religiones. Madrid, Instituto de Estudios Políticos, 1954.

El mito del eterno retorno. México, Planeta, 1985.

Lo sagrado y lo profano. 9a. edición. Bogotá, Ed. Labor, 1996.

FERRARI, Américo

"Moro el extranjero». En Hueso Húmero. Lima, No. 2, julio-septiembre de 1979; pp. 106-109.

Los sonidos del silencio. Poetas peruanos en el siglo XX.

Lima, Mosca Azul, 1990.

HIGGINS, James

"Westphalen, Moro y la poética surrealista». En Cielo

Abierto. Lima, No. 29, julio-septiembre de 1984;

pp. 16-26.

Hitos de la poesía peruana: siglo XX. Lima, Milla

Batres, 1993

HUIDOBRO, Vicente

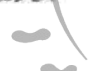

Poesía y poética. Antología comentada por René de Costa.

Madrid, Âliâtzafaditoral, 1996, as

MORO, César "Jorge Puccinelli Converso»

Le château du grisou. México, Ed. Trigondine, 1943.

La tortuga ecuestre y otros poemas, 1924-1949. Edición de André Coyné. México, Trigondine, 1957.

Los anteojos de azufre. Prosas reunidas y presentadas por André Coyné. Lima, Ed. San Marcos, 1958.

La tortuga ecuestre y otros textos. Selección y edición de Julio Ortega. Caracas, Monte Avila, 1976.

Versiones del surrealismo. Prólogo y edición de Julio Ortega. Barcelona, Ed. Tusquets, 1974.

Obra poética I. Prefacio de André Coyné. Edición, prólogo y notas de Ricardo Silva-Santisteban. Bibliografía por Miguel Angel Rodríguez Rea. Lima, INC, 1980. 
NADEAU, Maurice

Historia del surrealismo. Barcelona, Ariel, 1972.

ORTEGA, Julio

«La poesía de César Moro». En La imaginación crítica. Lima, Peisa, 1974, pp. 145-159.

OVIEDO, José Miguel

"Sobre la poesía de César Moro». En Lexis. Revista de Lingüística y Literatura. Lima, PUC, vol. 1, No. 1, 1977, pp. 101-105.

RAMA, Angel

Transculturación narrativa en América Latina. 2a. ed. México, Siglo XXI, 1985.

REAL ACADEMIA ESPAÑOLA

Diccionarió de la lengua española. Vigésima primera edición. Madrid, Ed. Espasa-Calpe, 1995. 2 t.

SOBREVILLA, David «Surrealismo, homosexualidad y poesía». En: Avatares..., pp. $[167\}-188$. "Jorge Puccinelli Converso"

SUCRE, Guillermo

La máscara, la transparencia. Caracas, Ed. Monte Avila, 1975, pp. 398-404.

WESTPHALEN, Emilio Adolfo

Escritos varios sobre arte y poesía. México, Fondo de Cultura Económica, 1997.

«Digresión sobre surrealismo y sobre César Moro entre los surrealistas». En Avatares..., pp. [203]-216. 